Multienergy gold ion implantation for enhancing the field electron emission characteristics of heterogranular structured diamond films grown on Au-coated Si substrates

Peer-reviewed author version

KAMATCHI JOTHIRAMALINGAM, Sankaran; Manoharan, D.; Sundaravel, B. \& Lin, I. N. (2016) Multienergy gold ion implantation for enhancing the field electron emission characteristics of heterogranular structured diamond films grown on Au-coated Si substrates. In: APPLIED PHYSICS LETTERS, 109(10), p. 41-45 (Art № 101603).

DOI: $10.1063 / 1.4962537$

Handle: http://hdl.handle.net/1942/22694 


\title{
Multienergy gold ion implantation for enhancing the field electron emission characteristics of heterogranular structured diamond films grown on Au- coated Si substrates
}

\author{
K. J. Sankaran, ${ }^{1,2}$ D. Manoharan, ${ }^{3}$ B. Sundaravel, ${ }^{4}$ and I. N. $\operatorname{Lin}^{3, a)}$ \\ ${ }^{1}$ Institute for Materials Research (IMO), Hasselt University, Diepenbeek 3590, Belgium. \\ ${ }^{2} I M O M E C$, IMEC vzw, Diepenbeek 3590, Belgium. \\ ${ }^{3}$ Department of Physics, Tamkang University, Tamsui, Taiwan 251, Republic of China. \\ ${ }^{4}$ Materials Science Group, Indira Gandhi Centre for Atomic Research, Kalpakkam 603 102, India.
}

Multienergy Au-ion implantation enhanced the electrical conductivity of heterogranular structured diamond films grown on Au-coated Si substrates to a high level of $5076.0(\Omega \mathrm{cm})^{-1}$ and improved the field electron emission (FEE) characteristics of the films to low turn-on field of $1.6 \mathrm{~V} / \mu \mathrm{m}$, high current density of $5.4 \mathrm{~mA} / \mathrm{cm}^{2}(@ 2.65 \mathrm{~V} / \mu \mathrm{m})$ and high lifetime stability of $1825 \mathrm{~min}$. The catalytic induction of nanographitic phases in the films due to Au-ion implantation and the formation of diamond-to-Si eutectic interface layer due to Au-coating on $\mathrm{Si}$ together encouraged efficient conducting channels for electron transport, thereby improved the FEE characteristics of the films.

${ }^{a)}$ Electronic mail: inanlin@mail.tku.edu.tw

Field emitters with superior field electron emission (FEE) characteristics are employed as a cold cathode materials in flat panel displays and other electron emitting devices. ${ }^{1-3}$ Compared with the carbon-based field emitters, ${ }^{4-6}$ diamond possesses high FEE characteristics due to its negative electron affinity (NEA), ${ }^{7,8}$ which makes it a promising material for applications as FEE emitters. But owing to the wide bandgap nature of diamond, the electrical conductivity in bulk diamond is low, which decreases its electron emission. As a result, the high prospective that the diamond accepts as a cold cathode field emitting material necessitates the material to be conductive. Recently, main focus has been directed towards the synthesis of ultrananocrystalline 
diamond (UNCD) film, containing ultra-small diamond grains of 5-10 nm with smooth surface characteristics, which exhibits higher electrical conductivity and better FEE properties than other form of diamond films. ${ }^{9,10}$ The $\mathrm{sp}^{2}$-bonded carbon in the grain boundaries of UNCD films is conceived as the electron conduction channel in FEE. ${ }^{11-14}$ Though, the non-diamond carbons contained in the grain boundaries of UNCD films are not conductive enough, restricting the FEE characteristics achievable for diamond films. Thus, the diamond films of high $\mathrm{sp}^{3}$-bonded carbon content with grain boundaries phase of better conductivity are desperately needed for the development of better FEE materials.

In this letter, multienergy $\mathrm{Au}$ ions were implanted on heterogranular structured diamond (HGD) films grown on Au-coated Si substrates for improving their electrical conductivity and the FEE characteristics. The detailed microstructures of the multienergy Au-ion implanted HGD films were investigated using transmission electron microscopy and the role of Au in enhancing the FEE characteristics of these HGD films was discussed.

$100 \mathrm{~nm} \mathrm{Au}$ deposited $\mathrm{Si}(\mathrm{Au}(\mathrm{Si}))$ substrates were used to grow diamond films. Prior to $\mathrm{Au}$ deposition, a thin layer of $\mathrm{Cr}(\sim 5 \mathrm{~nm})$ was deposited on Si to achieve strong adhesion of $\mathrm{Au}$ on $\mathrm{Si}$. The process of $\mathrm{Au}$ and $\mathrm{Cr}$ deposition on $\mathrm{Si}$ and the pre-seeding process for the growth of diamond on these $\mathrm{Au}(\mathrm{Si})$ substrates are described in detail elsewhere. ${ }^{15,16} \mathrm{UNCD}$ films were first deposited using microwave plasma enhanced chemical vapor deposition (MPECVD) system in $\operatorname{Ar}(99 \%) / \mathrm{CH}_{4}(1 \%)$ plasma under $1200 \mathrm{~W}$ and 120 Torr for $90 \mathrm{~min}$. The plane view scanning electron microscopy (SEM; Jeol 6500) image shown in Fig. S1 of the supporting information depicts that the UNCD films have a very smooth surface. The high resolution transmission electron microscopy (HRTEM; Jeol 2100F) investigation (Fig. S2, supporting information) indicated that these films contain spherical ultra-small diamond grains $(\sim 5 \mathrm{~nm})$ with grain boundaries of considerable thickness $(\sim 0.2 \mathrm{~nm})$. Subsequently, a secondary MPECVD process using a $\operatorname{Ar}(49 \%) / \mathrm{H}_{2}(50 \%) / \mathrm{CH}_{4}(1 \%)$ gas with 55 Torr chamber pressure and $1500 \mathrm{~W}$ microwave power was performed for $120 \mathrm{~min} .{ }^{17}$ These films were designated as $\mathrm{HGD} / \mathrm{Au}(\mathrm{Si})$ films. The surface morphology of the $\mathrm{HGD} / \mathrm{Au}(\mathrm{Si})$ films appears faceted morphology with large diamond grains of micron size (inset "I" of Fig. 1(a)).

$\mathrm{Au}$ ions are then implanted in $\mathrm{HGD} / \mathrm{Au}(\mathrm{Si})$ films at various energies from $400 \mathrm{keV}$ to 3850 $\mathrm{keV}$ corresponding to ion ranges from $98 \mathrm{~nm}$ to $700 \mathrm{~nm}$ with different fluences, which is shown 
in Fig. 1(a), totaling to a fluence of $1 \times 10^{16}$ ions $/ \mathrm{cm}^{2}$ and the obtained films were designated as $\mathrm{Au}-\mathrm{HGD} / \mathrm{Au}(\mathrm{Si})$ films. The multienergy Au-ion implantation process rendered the surface morphology of $\mathrm{Au}-\mathrm{HGD} / \mathrm{Au}(\mathrm{Si})$ films to equi-axed nanosized diamond grains of size around 20-30 nm (inset "II" of Fig. 1(a)) that is contrary to the case when the UNCD films were implanted by single energy $500 \mathrm{keV}$ Au-ions with fluence of $1 \times 10^{17}$ ions $/ \mathrm{cm}^{2}$ (single AuUNCD) that resulted a featureless surface morphology for the UNCD films. ${ }^{18}$ The energy dispersive X-ray spectroscopy (EDX) spectrum (Fig. S3, supporting information) corresponding to the SEM image of $\mathrm{Au}-\mathrm{HGD} / \mathrm{Au}(\mathrm{Si})$ films (inset "II" of Fig. 1(a)) clearly shows the $\mathrm{Si}$ and $\mathrm{Au}$ peaks indicating the existence of $\mathrm{Si}$ and $\mathrm{Au}$ species in $\mathrm{Au}-\mathrm{HGD} / \mathrm{Au}(\mathrm{Si})$ films. To facilitate the comparison, the HGD films were also grown directly on $\mathrm{Si}$, followed by multienergy $\mathrm{Au}$-ion implantation process and thus obtained films were designated as $\mathrm{Au}-\mathrm{HGD} / \mathrm{Si}$.

The secondary ion mass spectroscopy (SIMS; Cameca IMS-4f) depth profile shown in Fig. 1(b) suggests that $\mathrm{Au}$ ions are distributed uniformly throughout the thickness of the implanted region (region "I" of Fig. 1(b)) of Au-HGD/Au(Si) films. This is contrary to the SIMS results of single Au-UNCD films, in which the Au ions are non-uniformly distributed to a depth of about $320 \mathrm{~nm}$ with peak concentration located at around $160 \mathrm{~nm}$ beneath the surface. ${ }^{18}$ Region "II" of Fig. 1(b) clearly shows that there are pronounced Au- and Si-ion counts observed in the interface layer, inferring the marked diffusion of $\mathrm{Au}$ and $\mathrm{Si}$ species into the interface layer. The $\mathrm{Au}(\mathrm{Si})$ counts drop rapidly away from the interface to the surface of diamond films. In addition, the $\mathrm{Cr}$ ions were also observed near to the interface of diamond and Si (region "II" of Fig. 1(b)), implying that the presence of $\mathrm{Cr}$ has evidently enhanced the adhesion of Au-layer.

Fig. 1(c) shows the visible-Raman spectra $\left(\lambda=632.0 \mathrm{~nm}\right.$, spectral resolution $0.5 \mathrm{~cm}^{-1}, \mathrm{Lab}$ Raman HR800, Jobin Yvon) of the I. HGD/Au(Si) and II. Au-HGD/Au(Si) films, which were deconvoluted using the multi-peak Lorentzian fitting method. Spectrum I in this figure shows that the Raman spectrum of the $\mathrm{HGD} / \mathrm{Au}(\mathrm{Si})$ films contains a sharp peak at $1336 \mathrm{~cm}^{-1}$ corresponding to sp ${ }^{3}$-bonded carbon (diamond) and the broadened peaks at around $1375 \mathrm{~cm}^{-1}$ (Dband) and $1536 \mathrm{~cm}^{-1}$ (G-band) are corresponding to the disordered and graphitic phase, respectively. ${ }^{19-21}$ There also exists a peak at around $1169 \mathrm{~cm}^{-1}$, which is attributed to the $v_{1}$ mode of trans-polyacetylene present in the grain boundaries. ${ }^{22}$ The existence of diamond peak at 1336 $\mathrm{cm}^{-1}$ is related to the formation of large diamond grains due to coalescence process that resulted 
in faceted micron-sized diamond grains in $\mathrm{HGD} / \mathrm{Au}(\mathrm{Si}$ ) films (cf. inset "I" of Fig. 1(a)). It is to be noted that in UNCD films (primary layered diamond films), all the Raman peaks are very broad (Fig. S4, supporting information) that is ascribed to the ultra-nano sized diamond grains in UNCD films. Spectrum II of Fig. 1(c) shows the effect of multienergy Au-ion implantation on altering the bonding characteristics of the $\mathrm{Au}-\mathrm{HGD} / \mathrm{Au}(\mathrm{Si})$ films. It shows higher intensity $\mathrm{D}$ and $\mathrm{G}$ peaks with noisy background, implying the amorphization or graphitization type of transitions with some blue shifting of the $G$ band. The Raman spectra show $I_{D} / I_{G}$ values (ratio of intensities of D-peak to G-peak) of 0.85 and 1.10 for $\mathrm{HGD} / \mathrm{Au}(\mathrm{Si})$ and $\mathrm{Au}-\mathrm{HGD} / \mathrm{Au}(\mathrm{Si})$ films, respectively. The increase of $\mathrm{I}_{\mathrm{D}} / \mathrm{I}_{\mathrm{G}}$ value from 0.85 to 1.10 implies the formation of nanographitic phase and decreases in $\mathrm{sp}^{3}$ content from amorphous carbon $(a-C)$ phase. ${ }^{22}$ The phenomenon that the peak related to diamond is not visible in $\mathrm{Au}-\mathrm{HGD} / \mathrm{Au}(\mathrm{Si})$ films can be attributed to the two possible interaction induced by the multienergy Au-ion implantation process: (1) the large grains in Au$\mathrm{HGD} / \mathrm{Au}(\mathrm{Si})$ films have been converted into nano-sized diamond grains and (2) the induction of large proportion of $\mathrm{sp}^{2}$-bonded carbon to which visible-Raman spectroscopy is more sensitive, as compared to those of $\mathrm{sp}^{3}$-bonded carbons. ${ }^{21}$ More detailed investigation on the microstructure/bonding structure of these films will be discussed later using electron energy loss spectroscopy (EELS; Gatan Enfina) in a transmission electron microscopy (TEM).

Hall measurements carried out in a van der Pauw configuration revealed that multienergy Au-ion implantation markedly improved the electrical conductivity of the films. The Au$\mathrm{HGD} / \mathrm{Au}(\mathrm{Si})$ films exhibit high electrical conductivity of $\sigma_{\mathrm{Au}-\mathrm{HGD} / \mathrm{Au}(\mathrm{Si})}=5076.0(\Omega \mathrm{cm})^{-1}$ with sheet carrier concentration of $n_{\mathrm{e}}=9.9 \times 10^{18} \mathrm{~cm}^{-2}$ and mobility of $\mu_{\mathrm{e}}=130.0 \mathrm{~cm}^{2} / \mathrm{V} \mathrm{s}$, which are superior than those of other conducting diamond films reported in literature (see Table I). ${ }^{18,23-28}$ In contrast, the $\mathrm{HGD} / \mathrm{Au}(\mathrm{Si})$ films possess lower $\sigma$-value of $207.2(\Omega \mathrm{cm})^{-1}\left(n_{\mathrm{e}}=3.6 \times 10^{17} \mathrm{~cm}^{-2}\right.$ and $\mu_{\mathrm{e}}=0.85 \mathrm{~cm}^{2} / \mathrm{V} \mathrm{s}$ ), whereas the Au-HGD/Si films, the $\sigma$-value is lower than that of Au$\mathrm{HGD} / \mathrm{Au}(\mathrm{Si})$ films, i.e., $\sigma_{\mathrm{Au}-\mathrm{HGD} / \mathrm{Si})}=828.4(\Omega \mathrm{cm})^{-1}\left(n_{\mathrm{e}}=3.2 \times 10^{18} \mathrm{~cm}^{-2}\right.$ and $\left.\mu_{\mathrm{e}}=75.8 \mathrm{~cm}^{2} / \mathrm{V} \mathrm{s}\right)$. Apparently, the multienergy Au-ion implantation process is the main factor, which converts the HGD films into highly conducting diamond films. The presence of Au-interlayer less markedly altered the Hall conductivity of the HGD films, as this Hall technique measures the conductivity along the surface rather than crossing the interface. 
The FEE behaviors of these highly conducting $\mathrm{Au}-\mathrm{HGD} / \mathrm{Au}(\mathrm{Si})$ films are shown in Fig. 2, which reveal the fascinating FEE properties of these films. The details of the FEE experiments are given elsewhere ${ }^{15}$ and the FEE properties of these films were analyzed using Fowler Nordheim (FN) theory. ${ }^{29}$ The plots of $\ln \left(J / E^{2}\right)-1 / E$ (curve I, Fig. 2(b)) show that the $E_{0}$ value of $1.60 \mathrm{~V} / \mu \mathrm{m}$ was attained for $\mathrm{Au}-\mathrm{HGD} / \mathrm{Au}(\mathrm{Si})$, which is lower than those of the $E_{0}$ values of $\mathrm{HGD} / \mathrm{Au}(\mathrm{Si})\left(\left(E_{0}\right)_{\mathrm{HGD} / \mathrm{Au}(\mathrm{Si})}=4.23 \mathrm{~V} / \mu \mathrm{m}\right.$; curve II, Fig. $\left.2(\mathrm{~b})\right)$ and Au-HGD/Si films $\left(\left(E_{0}\right)_{\mathrm{Au}-\mathrm{HGD} / \mathrm{Si}}\right.$ $=4.47 \mathrm{~V} / \mu \mathrm{m}$; curve III, Fig. 2(b)). To reach a large $J$-value of $3.0 \mathrm{~mA} / \mathrm{cm}^{2}$, it needs an applied field of $E=2.48 \mathrm{~V} / \mu \mathrm{m}$ for Au-HGD/Au(Si) films (curve I, Fig. 2(a)), which is smaller than those for $\mathrm{HGD} / \mathrm{Au}(\mathrm{Si})\left((E)_{\mathrm{HGD} / \mathrm{Au}(\mathrm{Si})}=7.50 \mathrm{~V} / \mu \mathrm{m}\right.$; curve II, Fig. 2(b)) and Au-HGD/Si films $\left((E)_{\mathrm{Au}-}\right.$ $\mathrm{HGD} / \mathrm{Si}=6.56 \mathrm{~V} / \mu \mathrm{m}$; curve III, Fig. 2(b)). The effective work functions of these diamond films calculated from the slope of the FN plots (Fig. 2(b)) are $\left(\varphi_{\mathrm{eff}}\right)_{\mathrm{Au}-\mathrm{HGD} / \mathrm{Au}(\mathrm{Si})}=0.0127 \mathrm{eV}$ for Au$\mathrm{HGD} / \mathrm{Au}(\mathrm{Si})$ films and $\left(\varphi_{\mathrm{eff}}\right)_{\mathrm{HGD} / \mathrm{Au}(\mathrm{Si})}=0.0250$ and $\left(\varphi_{\mathrm{eff}}\right)_{\mathrm{Au}-\mathrm{HGD} / \mathrm{Si}}=0.0197 \mathrm{eV}$ for $\mathrm{HGD} / \mathrm{Au}(\mathrm{Si})$ and $\mathrm{Au}-\mathrm{HGD} / \mathrm{Si}$ films, respectively, revealing a low work function value for $\mathrm{Au}-\mathrm{HGD} / \mathrm{Au}(\mathrm{Si})$ films. In addition, $\mathrm{Au}-\mathrm{HGD} / \mathrm{Au}(\mathrm{Si})$ films shows a good lifetime stability. The FEE $J$ versus time curve is displayed in the inset of Fig. 2(a), signifying the emission current variations recorded over a period of $1825 \mathrm{~min}$ at a working field of $2.4 \mathrm{~V} / \mu \mathrm{m}$, corresponding to a $J$ of $1.5 \mathrm{~mA} / \mathrm{cm}^{2}$, for $\mathrm{Au}-\mathrm{HGD} / \mathrm{Au}(\mathrm{Si})$ films. Consequently, the $\mathrm{Au}-\mathrm{HGD} / \mathrm{Au}(\mathrm{Si})$ films exhibit a far more efficient FEE behavior, viz. lower $E_{0}$, higher $J$ and longer lifetime as compared with the other conducting diamond based field emitters, that are summarized in Table I. ${ }^{18,23-28}$

TEM examination has been carried out to elucidate the source of enhancement on the electrical conductivity and FEE behavior of $\mathrm{Au}-\mathrm{HGD} / \mathrm{Au}(\mathrm{Si})$ films. Fig. 3(a) shows the typical bright field (BF) TEM micrograph for the $\mathrm{Au}-\mathrm{HGD} / \mathrm{Au}(\mathrm{Si})$ films. The corresponding selective area diffraction (SAED) pattern (inset, Fig. 3(a)) contains sharp diffraction rings corresponding to the (111), (220) and (311) diamond lattices, which confirm that the nanosized clusters are of diamond structure. A diffused ring appears in the center of the SAED pattern, indicating the existence of the $\mathrm{sp}^{2}$-bonded carbon (graphitic or $a$ - $C$ phase). Dark-field images were taken from different parts of SAED, i.e., from the diffraction spots corresponding to diamond and graphite separately and the images were then superimposed to clearly illustrate the distribution of these phase constituents. Figure 3(b) clearly shows that the graphitic phases (green color) were 
uniformly distributed among the diamond grains (pink, blue, and yellow colors) in Au$\mathrm{HGD} / \mathrm{Au}(\mathrm{Si})$ films.

More detailed microstructure of $\mathrm{Au}-\mathrm{HGD} / \mathrm{Au}(\mathrm{Si})$ films was exemplified by HRTEM studies. Fig. 3(c) shows the structure image corresponding to region "A" in the BF-TEM image of Fig. 3(a). Fourier transformed (FT) diffractogram image of the entire structure image $\left(\mathrm{FT}_{0}\right)$ in Fig. 3(c) shows a spotted diffraction pattern arranged in ring, suggesting nano-sized nature of the diamond (D) phases. The donut-shaped diffused diffraction ring located at the center of $\mathrm{FT}_{0}$ image indicated that the $\mathrm{sp}^{2}$-bonded carbon corresponds to graphitic (G) phase rather than $a-C$ phase. The existences of diamond (D) phase is highlighted by region " 1 " and that of the graphitic phases by regions " 2 " and " 3 " and are identified by the FT images $\mathrm{FT}_{1}-\mathrm{FT}_{3}$, respectively. Sometime, the whole nano-sized diamond grains were converted into nanographite clusters, which is illustrated as curved fringes in region "5" of Fig. 3(d), which is the structure image corresponding to region "B" of the BF-TEM image (Fig. 3(a)). The corresponding $\mathrm{FT}_{5}$-image shows a central diffuse ring of donut geometry, clearly indicates that the curved fringes in region " 5 " are nanographite clusters about $5 \mathrm{~nm}$ in size, which is the same size of a diamond grains in small-grain regions of HGD films. ${ }^{17}$

Figure 3(e) shows selective area core-loss EELS spectrum of Au-HGD/Au(Si) films signifying a small hump, denoting $\mathrm{sp}^{2}$-bonded carbon $\left(\sim 285 \mathrm{eV}, \pi^{*}\right.$-band), besides the typical EELS signal of $\mathrm{sp}^{3}$-bonded carbon, which includes a sharp peak at $\sim 292 \mathrm{eV}$ ( $\sigma^{*}$-band) and a dip in the vicinity of $\sim 302 \mathrm{eV} .{ }^{30-32}$ Fig. 3(f) shows the selective area plasmon-loss EELS spectrum of the same region as that for core-loss EELS spectrum of $\mathrm{Au}-\mathrm{HGD} / \mathrm{Au}(\mathrm{Si})$ films. The detailed deconvolution of this spectrum indicated that the $\mathrm{Au}-\mathrm{HGD} / \mathrm{Au}(\mathrm{Si})$ films are dominated by $\mathrm{S}_{2}$ $(\sim 23 \mathrm{eV})$ and $\mathrm{S}_{4}(\sim 33 \mathrm{eV})$ bands along with the $\mathrm{S}_{3}$-band $(\sim 27 \mathrm{eV}),{ }^{31}$ representing that the region comprises of some graphitic phases with no $22 \mathrm{eV}$ peak corresponding to $a-C$ phase besides the diamond phases. On the basis of TEM and EELS investigations for the Au-HGD/Au(Si) films, it is noticed that multienergy $\mathrm{Au}$-ion implantation process induces primarily the formation of nanographitic phases.

To be as a very good electron field emitter, the critical point is the supply of adequate electrons from the substrates (the $\mathrm{Si}$ ) to the emitting sites (the diamond), besides the low work function of the emitting surface. Both the electrical conductivity of the diamond and the 
resistance of diamond-to-Si interface need to be optimized for improving the effectiveness for the supply of electrons. These two critical requirements are concurrently satisfied by the incorporation of $\mathrm{Au}$ species in the diamond films that were either precoated on $\mathrm{Si}$ substrates prior to the growth of diamond films or were implanted into the diamond films. This is illustrated in region II of SIMS (cf. Fig. 1(b)) that there is a formation of $\mathrm{Au}(\mathrm{Si})$ eutectic layer in the interface between diamond and $\mathrm{Si}$ due to the utilization of $\mathrm{Au}$ coating. Hence, the formation of $\mathrm{Au}(\mathrm{Si})$ eutectic layer eliminates the origin of the $a-C$ phase in the vicinity of interface, which lowers the resistivity of the interface layer. ${ }^{15,16}$ Seemingly, the $\mathrm{SiC}$ was formed due to the interaction of $\mathrm{Si}$ and $\mathrm{C}$ species, i.e., the $\mathrm{Si}$ species have diffused through the $\mathrm{Au}(\mathrm{Si})$ eutectic layer to react with the carbon promptly, forming $\mathrm{SiC}$. The $\mathrm{SiC}$ can enhance the efficiency for the nucleation of diamond. ${ }^{16}$ On the other hand, the region I of SIMS studies (cf. Fig. 1(b)) revealed that the multienergy Au-ions implanted into the HGD films were uniformly distributed throughout the thickness of the films. The presence of Au in HGD films can catalytically induce the formation of the grain boundary phase and even converts the whole nano-sized diamond grains into nanographitic clusters that improve the electrical conductivity of the films. ${ }^{33,34}$ Restated, both the conductivity of diamond-to-Si interface and the bulk diamond films were enhanced due to the $\mathrm{Au}$-coating and $\mathrm{Au}$-ion implantation, respectively. Therefore, the electrons can be transferred effortlessly from $\mathrm{Si}$ substrate across the interfacial layer to the diamond region and can move through the conduction channels of the diamond grains to the emitting surface and are then emitted to vacuum easily as the diamond surfaces are NEA in nature. ${ }^{7,8}$

In summary, a feasible way of fabricating highly conducting $\mathrm{Au}-\mathrm{HGD} / \mathrm{Au}(\mathrm{Si})$ films with enhanced FEE properties due to multienergy Au-ion implantation process and the use of $\mathrm{Au}(\mathrm{Si})$ eutectic layer, is demonstrated. The catalytic induction of nanographitic phases in the grain boundaries due to $\mathrm{Au}$-ion implantation advances the conducting nature of the films. Besides, the formation of $\mathrm{Au}(\mathrm{Si})$ eutectic layer due to Au-coating induces the formation of $\mathrm{SiC}$ phases in the interface that efficiently nucleating the diamond, eliminating the formation of $a-C$ phase, and improves the transport of electrons crossing the diamond-to-Si interface. Consequently, the superior FEE characteristics of conducting $\mathrm{Au}-\mathrm{HGD} / \mathrm{Au}(\mathrm{Si})$ films are achieved which may open up a pathway for the application in high-definition flat panel displays or plasma devices. 


\section{Supplementary Material}

See supplementary material for SEM, Raman and HRTEM studies of UNCD films and EDX spectrum of $\mathrm{Au}-\mathrm{HGD} / \mathrm{Au}(\mathrm{Si})$ films.

The authors like to thank the financial support of Ministry of Science and Technology, Taiwan through the project Nos. MOST 104-2112-M-032-003. K. J. Sankaran is a Postdoctoral Research Fellow of the Research Foundations-Flanders (FWO).

${ }^{1}$ W. Zhu, G. P. Kochanski, and S. Jin, Science 282, 1471 (1998).

${ }^{2}$ K. Okano, K. Hoshina, M. Iida, S. Koizumi, and T. Inuzuka, Appl. Phys. Lett. 64, 2742 (1994).

${ }^{3}$ W. L. Wang, J. D. Fabbri, T. M. Willey, J. R. I. Lee, J. E. Dahl, R. M. K. Carlson, P. R. Schreiner, A. A. Fokin, B. A. Tkachenko, N. A. Fokina, W. Meevasana, N. Mannella, K. Tanaka, X. J. Zhou, T. van Buuren, M. A. Kelly, Z. Hussain, N. A. Melosh, and Z.-X. Shen, Science 316, 1460 (2007).

${ }^{4}$ A. M. Rao, D. Jacques, R. C. Haddon, W. Zhu, C. Bower, and S. Jin, Appl. Phys. Lett. 76, 3813 (2000).

${ }^{5}$ H. Kiyota, H. Araki, H. Kobayashi, T. Shiga, K. Kitaguchi, M. Iida, H. Wang, T. Miyo, T. Kurosu, K. Inoue, I. Saito, M. Nishitani Gamo, I. Sakaguhi and T. Ando, Appl. Phys. Lett. 75, 2331 (1999).

${ }^{6}$ B. S. Satyanarayana, A. Hart, W. I. Milne, and J. Robertson, Appl. Phys. Lett. 71, 1431 (1997).

${ }^{7}$ M. W. Geis, N. N. Efremow, K. E. Krohn, J. C. Twichell, T. M. Lyszczarz, R. Kalish, J. A. Greer, and M. D. Tabat, Nature 393, 431 (1998).

${ }^{8}$ H. Yamaguchi, T. Masuzawa, S. Nozue, Y. Kudo, I. Saito, J. Koe, M. Kudo, T. Yamada, Y. Takakuwa, and K. Okano, Phys. Rev. B 80, 165321 (2009).

${ }^{9}$ A. R. Krauss, O. Auciello, M. Q. Ding, D. M. Gruen, Y. Huang, V. V. Zhirnov, E. I. Givargizov, A. Breskin, R. Chechen, E. Shefer, V. Konov, S. Pimenov, A. Karabutov, A. Rakhimov, and N. Suetin, J. Appl. Phys. 89, 2958 (2001).

${ }^{10}$ D. Zhou, D. M. Gruen, L. C. Qin, T. G. McCauley, and A. R. Krauss, J. Appl. Phys. 84(4), 1981 (1998). 
${ }^{11}$ E. J. Correa, Y. Wu, J. G. Wen, R. Chandrasekharan, and M. A. Shannon, J. Appl. Phys. 102, 113706 (2007).

${ }^{12}$ X. Lu, Q. Yang, C. Xiao, and A. Hirose, Thin Solid Films 516, 4217 (2008).

${ }^{13}$ K. J. Sankaran, K. Panda, B. Sundaravel, N. H. Tai, and I. N. Lin. J. Appl. Phys. 115, 063701 (2014).

${ }^{14}$ H. C. Chen, U. Palnitkar, W. F. Pong, I. N. Lin, A. P. Singh, and R. Kumar, J. Appl. Phys. 105, 083707 (2009).

${ }^{15}$ K. J. Sankaran, K. Panda, B. Sundaravel, H. C. Chen, I. N. Lin, C. Y. Lee, and N. H. Tai, ACS Appl. Mater. Interfaces 4, 4169 (2012).

${ }^{16}$ H. C. Chen, K. J. Sankaran, S. C. Lo, L. J. Lin, N. H. Tai, C. Y. Lee, and I. N. Lin, J. Appl. Phys. 112, 103711 (2012).

${ }^{17}$ C. S. Wang, H. C. Chen, H. F. Cheng, and I. N. Lin, J. Appl. Phys. 107, 034304 (2010).

${ }^{18}$ K. J. Sankaran, H. C. Chen, C. Y. Lee, N. H. Tai, and I. N. Lin, Appl. Phys. Lett. 102, 061604 (2013).

${ }^{19}$ A. C. Ferrari and J. Robertson, Phys. Rev. B: Condens. Matter Mater. Phys. 63, 121405 (2001).

${ }^{20}$ J. Michler, Y. Von Kaenel, J. Stiegler and E. Blank, J. Appl. Phys. 81(1), 187 (1998).

${ }^{21}$ A. C. Ferrari and J. Robertson, Phys. Rev. B: Condens. Matter Mater. Phys. 61, 14095 (2000).

${ }^{22}$ Z. Sun, J. R. Shi, B. K. Tay and S. P. Lau, Diamond Relat. Mater. 9, 1979 (2000).

${ }^{23}$ R. Arenal, P. Bruno, D. J. Miller, M. Bleuel, J. Lal, and D. M. Gruen, Phys. Rev. B 75, 195431 (2007).

${ }^{24}$ X. J. Hu, J. S. Ye, H. J. Liu, Y. G. Shen, X. H. Chen, and H. Hu, J. Appl. Phys. 109, 053524 (2011).

${ }^{25}$ X. J. Hu, J. S. Ye, H. Hu, X. H. Chen, and Y. G. Shen, Appl. Phys. Lett. 99, 131902 (2011).

${ }^{26}$ K. J. Sankaran, K. Panda, B. Sundaravel, N. H. Tai, and I. N. Lin, J. Appl. Phys. 115, 063701 (2014).

${ }^{27}$ K. J. Sankaran, K. Panda, B. Sundaravel, N. H. Tai, and I. N. Lin, J. Mater. Chem. C 3, 2632 (2015).

${ }^{28}$ K. J. Sankaran, Y. F. Lin, W. B. Jian, H. C. Chen, K. Panda, B. Sundaravel, C. L. Dong, N. H. Tai, and I. N. Lin, ACS Appl. Mater. Interfaces 5, 1294 (2013).

${ }^{29}$ R. H. Fowler and L. Nordheim, Proc. R. Soc. London, Ser. A 119, 173 (1928). 
${ }^{30}$ D. M. Gruen, S. Liu, A. R. Krauss, J. Luo, and X. Pan, Appl. Phys. Lett. 64(12), 1502 (1994).

${ }^{31}$ P. Kovarik, E. B. D. Bourdon, and R. H. Prince, Phys. Rev. B 48, 12123 (1993).

${ }^{32}$ I. Jimenez, M. M. Garcia, J. M. Albella, and L. J. Terminello, Appl. Phys. Lett. 73, 2911 (1998).

${ }^{33}$ A. Oya and S. Otani, Carbon 17, 131 (1979).

${ }^{34}$ W. Lu, K. Komvopoulos and S. W. Yeh, J. Appl. Phys. 89, 2422 (2001). 
TABLE I. Comparison between the electrical conductivity and the field electron emission characteristics of $\mathrm{Au}-\mathrm{HGD} / \mathrm{Au}(\mathrm{Si})$ films and other conducting diamond films.

\begin{tabular}{|c|c|c|c|}
\hline Materials & $\begin{array}{c}\text { Electrical } \\
\text { conductivity } \\
(\Omega \mathrm{cm})^{-1}\end{array}$ & $\begin{array}{l}\text { Turn-on field } \\
\qquad(\mathrm{V} / \mu \mathrm{m})\end{array}$ & $\begin{array}{c}\text { FEE current } \\
\text { density } \\
\left(\mathrm{mA} / \mathrm{cm}^{2}\right)\end{array}$ \\
\hline Au-ion implanted UNCD/Si ${ }^{18}$ & 185.0 & 4.7 & $4.5 @ 8.1 \mathrm{~V} / \mu \mathrm{m}$ \\
\hline $\mathrm{N}$-ion implanted UNCD/Si ${ }^{23}$ & -- & 8.8 & $5.4 @ 20.0 \mathrm{~V} / \mu \mathrm{m}$ \\
\hline O-ion implanted UNCD/ $\mathrm{Si}^{24}$ & 33.3 & -- & -- \\
\hline P-ion implanted UNCD/Si ${ }^{25}$ & 0.09 & -- & -- \\
\hline $\mathrm{Cu}$-ion implanted UNCD/ $\mathrm{Si}^{26}$ & 95.0 & 4.8 & $3.6 @ 8.0 \mathrm{~V} / \mu \mathrm{m}$ \\
\hline Pt-ion implanted UNCD/Si ${ }^{27}$ & 94.0 & 4.17 & $5.1 @ 7.2 \mathrm{~V} / \mu \mathrm{m}$ \\
\hline Nitrogen doped diamond nanowires ${ }^{28}$ & 186.0 & 4.35 & $3.4 @ 9.1 \mathrm{~V} / \mu \mathrm{m}$ \\
\hline $\mathrm{Au}-\mathrm{HGD} / \mathrm{Au}(\mathrm{Si})^{\text {This study }}$ & 5076.0 & 1.60 & $5.4 @ 2.6 \mathrm{~V} / \mu \mathrm{m}$ \\
\hline
\end{tabular}




\section{Figure captions}

FIG. 1. (a) Multienergy implantation scheme showing Au concentration profile simulated using the SRIM program with SEM images of I. HGD/Au(Si) and II. Au-HGD/Au(Si) films shown as insets; (b) SIMS depth profiles of C, Au, Cu and Si species in Au-HGD/Au(Si) films; (c) visibleRaman spectra of I. HGD/Au(Si) and II. Au-HGD/Au(Si) films.

FIG. 2. (a) Field electron emission characteristics (current density-applied field, $J$-E, curves) measured in high vacuum environment for I. Au-HGD/Au(Si), II. HGD/Au(Si) and III. AuHGD/Si films; (b) The Fowler Nordheim (FN) plots corresponding to the $J-E$ curves in "a". The inset of "a" shows the lifetime stability measurements ( $J$-time curves) for Au-HGD/Au(Si) films.

FIG. 3. The (a) bright-field with corresponding SAED pattern shown as inset and (b) dark field TEM micrographs of Au-HGD/Au(Si) films; (c) and (d) HRTEM images of Au-HGD/Au(Si) films, corresponding to the regions " $\mathrm{A}$ " and "B" of "a", respectively. The inset $\mathrm{FT}_{0}$ of "a" show the Fourier-transformed images corresponding to the whole structure image. The $\mathrm{FT}_{1}-\mathrm{FT}_{5}$ images show the FT images corresponding to regions " $1-5$ " of "c" and "d", respectively; (e) carbon edge core-loss EELS spectrum and (f) plasmon-loss EELS spectrum of Au-HGD/Au(Si) films. 

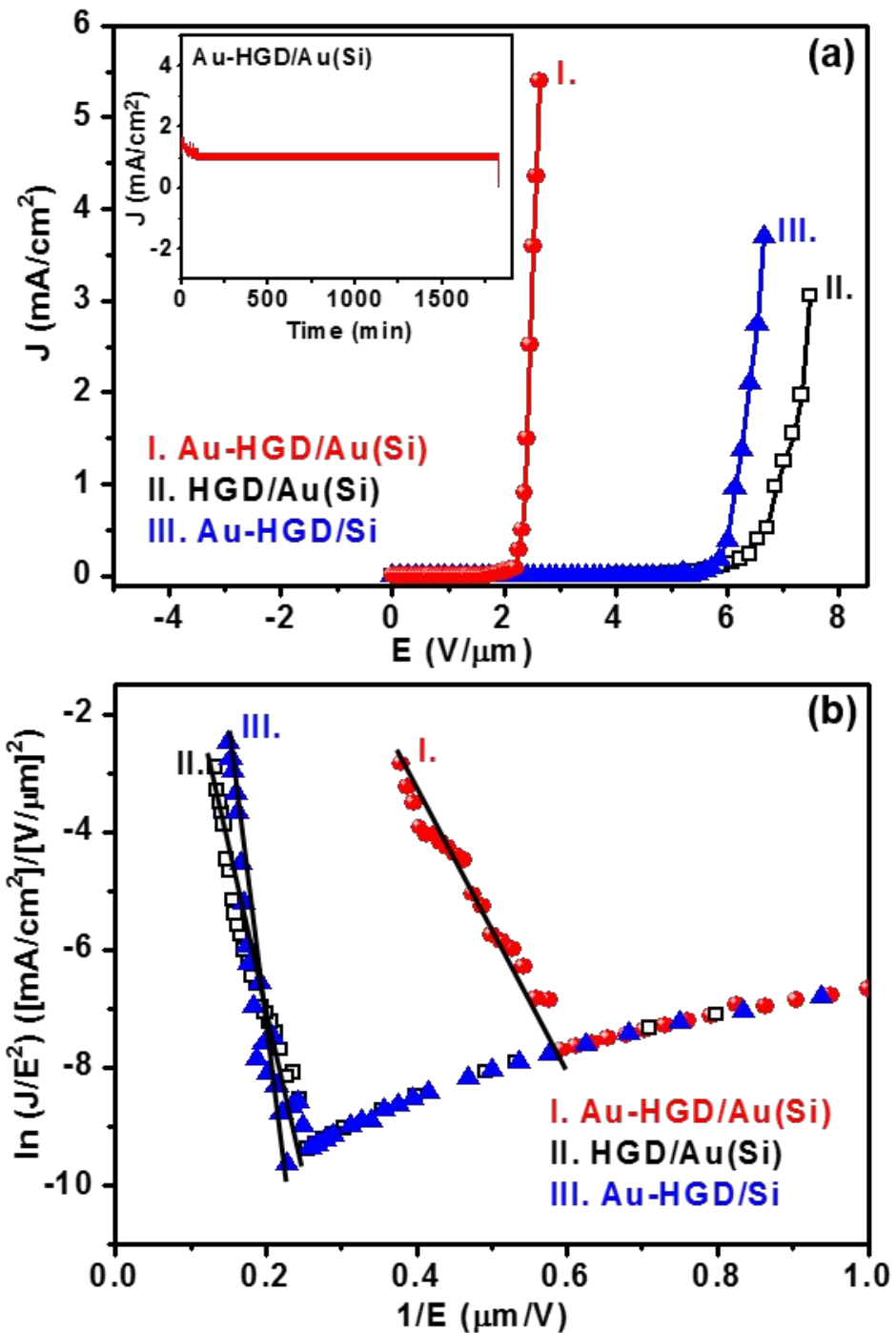
